\title{
Chronic kidney disease and measurement of albuminuria or proteinuria: a position statement
}

\section{David W Johnson MBBS (Hons), PhD, FRACP Nephrologis Graham R D Jones MBBS, MSc(Med), DPhil, Chemical Pathologist \\ Timothy H Mathew MBBS, FRACP Medical Director \\ Marie J Ludlow BA(Hons), PhD, National Medical Projects Manager ${ }^{3}$ \\ Stephen J Chadban MBBS, FRACP, PhD Nephrologist 4 \\ Tim Usherwood $M D, B S$, FRACGP \\ Professor of General Practice \\ Kevan Polkinghorne \\ MClinEpi, PhD, FRACP Nephrologist \\ Stephen Colagiuri MD, FRACP \\ Professor of Metabolic Health \\ George Jerums \\ AM, MBBS, MD, FRACP Endocrinologist $^{8}$ \\ Richard Maclsaac MBBS, PhD, FRACP Endocrinologist \\ Helen Martin BSc, MAACB, FAACB Clinical Biochemist \\ Australasian Proteinuria Consensus \\ Working Group}

1Department of Nephrology, Princess Alexandra Hospital, Brisbane, QLD.

2Department of Chemical

Pathology, St Vincent's

Hospital, Sydney, NSW.

3 Kidney Health Australia Adelaide, SA

4 Sydney Medical School,

University of Sydney, Sydney, NSW.

5 Department of General

Practice, Sydney Medical

School Westmead, Sydney, NSW

6Department of Nephrology.

Monash Medical Centre, Melboume, VIC

7 Boden Institute of Obesity

Nutrition and Exercise,

University of Sydney, Sydney, NSW.

8Department of

Endocrinology and Diabetes

St Vincent's Hospital, Melboume, VIC.

9 Gribbles Pathology, Adelaide, SA.

marie.ludlow@

kidney.org.au

doi: 10.5694/mjall.11468

An abridged version of this article appeared in the printed journal hronic kidney disease (CKD), defined as reduced kidney function (glomerular filtration rate [GFR] $<60 \mathrm{~mL} / \mathrm{min} / 1.73 \mathrm{~m}^{2}$ ) and/or evidence of kidney damage (usually indicated by albuminuria or proteinuria) for a period of at least 3 months, ${ }^{1}$ is a major public health problem in Australia and throughout the world. Based on data from the Australian Diabetes, Obesity and Lifestyle (AusDiab) Study, ${ }^{2,3}$ it is estimated that about 6 million individuals have one or more of the major risk factors for CKD and that about 1.4 million Australian adults have CKD.

Early identification and management of CKD is highly cost-effective and can reduce the risk of kidney failure progression and cardiovascular disease by up to $50 \%{ }^{4}$ Therefore, increasing the recognition of kidney damage and impaired kidney function, which is often asymptomatic, is a key part of improving health outcomes in the community.

Previously, work by the Australasian Creatinine Consensus Working Group has resulted in automatic reporting of an estimated GFR (eGFR) with requests for serum creatinine concentration in individuals aged $\geqslant 18$ years and unification of units of measurement for creatinine and GFR, and has promoted standardisation of assays. ${ }^{5,6}$ However, not all patients with CKD have a reduced eGFR, and a significant proportion can only be detected by assessing albuminuria or proteinuria. In the AusDiab study, $57 \%$ of subjects with albuminuria or proteinuria did not have an eGFR $<60 \mathrm{~mL} / \mathrm{min} / 1.73 \mathrm{~m}^{2}$. Large population studies have consistently shown that albuminuria and proteinuria strongly and independently predict the risks of CKD progression, cardiovascular disease and all-cause mortality in both diabetic and non-diabetic individuals. ${ }^{7-12}$ Moreover, combining albuminuria measurement with eGFR provides synergistic, complementary risk stratification for both cardiovascular disease and CKD. 7,8,10,13

An audit of primary care records of patients aged 50-75 years who had either hypertension or diabetes showed that only $29 \%$ noted a test for proteinuria within the preceding 12 months. ${ }^{14}$ Moreover, results from two recent surveys of pathology laboratories indicated a lack of standardisation regarding the choice of urinary protein test, units of reporting, and age and sex reference ranges. ${ }^{15,16}$

In response to these issues, a working group met throughout 2009 to 2011 to develop recommendations on the measurement of urinary albumin and protein (see Box 1 for definitions of terms used in this document). The working group process was sponsored by the Dialysis Nephrology Transplantation Subcommittee of the Australian and New Zealand Society of Nephrology (ANZSN) and consisted of representatives from the ANZSN, the Australasian Association of Clinical Biochemists, the Royal College of Pathologists of Australasia, the Royal Australian College of General Practitioners (RACGP), the Australian
Summary

- Optimal detection and subsequent risk stratification of people with chronic kidney disease (CKD) requires simultaneous consideration of both kidney function (glomerular filtration rate [GFR]) and kidney damage (as indicated by albuminuria or proteinuria).

- Measurement of urinary albuminuria and proteinuria is hindered by a lack of standardisation regarding requesting, sample collection, reporting and interpretation of tests.

- A multidisciplinary working group was convened with the goal of developing and promoting recommendations that achieve consensus on these issues.

- The working group recommended that the preferred method for assessment of albuminuria in both diabetic and non-diabetic patients is urinary albumin-tocreatinine ratio (UACR) measurement in a first-void spot urine specimen. Where a first-void specimen is not possible or practical, a random spot urine specimen for UACR is acceptable.

- The working group recommended that adults with one or more risk factors for CKD should be assessed using UACR and estimated GFR every $1-2$ years, depending on their risk-factor profile.

- Recommended testing algorithms and sex-specific cut-points for microalbuminuria and macroalbuminuria are provided.

- The working group recommended that all pathology laboratories in Australia should implement the relevant recommendations as a vital component of an integrated national approach to detection of CKD.

Diabetes Society and Kidney Health Australia. Paediatric issues and measurement of albuminuria and proteinuria for the purposes of monitoring patients with CKD were considered beyond the scope of this process.

A meeting of stakeholders was subsequently held in February 2011, including 38 representatives from the aforementioned organisations, representatives from the Australian Practice Nurses Association and consumer representatives. The following evidence-based recommendations ${ }^{17,18}$ emanated from this meeting. All recommendations were endorsed by most representatives. All recommendations contained in this position statement are endorsed by the parent bodies of this process.

\section{Recommendations}

\section{Preferred method of testing for albuminuria in the detection of CKD}

Measuring albumin level to detect CKD is already recommended for individuals with diabetes mellitus because the 


\section{Definitions}

Albuminuria: The presence of excessive amounts of the protein albumin in the urine. Microalbuminuria* is a slightly high level, indicated by a urinary albumin-to-creatinine ratio (UACR) of

$2.5-25 \mathrm{mg} / \mathrm{mmol}$ for men and $3.5-35 \mathrm{mg} / \mathrm{mmol}$ for women.

Macroalbuminuria is indicated by a UACR of more than $25 \mathrm{mg} / \mathrm{mmol}$ for men and more than $35 \mathrm{mg} / \mathrm{mmol}$ for women.

First-void (or first morning) specimen: The first urine void, collected after the individual wakes up in the morning.

Proteinuria: The presence of excessive amounts of proteins (>150 mg per day) in the urine. These proteins typically include albumin, low-molecular-weight immunoglobulins, lysozyme, insulin and $\beta_{2}$-microglobulin. Albuminuria and proteinuria are related entities but cannot be considered to be interchangeable.

Spot specimen: A collection from a single episode of passing urine, which need not consist of the entire volume of urine passed at that time. Spot specimens can be specified according to time of day or in relation to an event. A first morning spot specimen is the first urine passed after waking in the morning. A random spot specimen is one where the time of day is not specified (ie, usually not first morning). A spot specimen is distinguished from a timed specimen where the entire volume of urine produced in a specified time period is collected.

* Traditionally defined as a level of urinary albumin excretion that was above the normal range and below the detection threshold of standard urinary protein dipsticks.

bulk of published evidence linking screening or treatments with clinical outcomes has centred on testing for albuminuria. ${ }^{19,20}$ It has not yet been established whether testing for albuminuria or proteinuria is superior for detecting $\mathrm{CKD}$ or determining risk of progression in individuals who do not have diabetes. ${ }^{21,22}$ However, a recent retrospective longitudinal cohort study of 5586 people with CKD at a single renal centre showed that UACR performed as well as urinary protein-to-creatinine ratio (UPCR) and 24-hour urinary albumin and protein measurements in predicting doubling of serum creatinine, commencement of renal replacement therapy and all-cause mortality. ${ }^{23}$

The working group recommended initial testing for albuminuria rather than proteinuria as the preferred strategy in most individuals at risk of CKD on the basis that laboratory measurement of albuminuria:

- has been shown in population studies to accurately predict kidney and cardiovascular risks, and intervention trials have shown a renoprotective benefit associated with a reduction in urinary albumin; $8,10,12,24-27$

- exhibits greater sensitivity for detecting low-grade but clinically important albuminuria; ${ }^{28}$

- provides improved analytical precision at low, yet diagnostically important, concentrations; ${ }^{28}$

- allows assay standardisation, ${ }^{29}$

- has been established to be cost-effective compared with protein or albumin reagent strips; ${ }^{21}$ and

- is favoured by a number of other international bestpractice guidelines. ${ }^{19,20,22,30-33}$

Albumin is the most commonly increased urinary protein in most nephropathies. Furthermore, the simplified initial testing strategy of urinary albumin assessment in all individuals at risk of CKD was considered highly desirable by the working group.

The principal disadvantages of selecting albuminuria in preference to proteinuria for CKD screening among individuals who don't have diabetes are that the evidence base for CKD intervention strategies based on proteinuria is greater than it is for albuminuria, that proteinuria has traditionally been measured in some specific clinical settings (eg, pre-eclampsia), ${ }^{34}$ and that tubular proteinuria may be missed in a small number of individuals (eg, children with Fanconi syndrome and adults with multiple myeloma). The working group felt that the clinical risk of missing tubular proteinuria was low and was outweighed by the benefits of recommending UACR in preference to UPCR for CKD assessment.

Although dipstick testing of urine with protein or albumin reagent strips has long been established in clinical practice and has often been recommended for early detection of CKD in patients who do not have diabetes, ${ }^{35-38}$ its usefulness as an early detection strategy is significantly limited by poor sensitivity, marked operator dependency and limited evidence of its cost-effectiveness in high-risk populations. ${ }^{22,39-41}$ A recent analysis of the AusDiab study showed that, for the detection of a laboratory-confirmed $\mathrm{UACR} \geqslant 30 \mathrm{mg} / \mathrm{g}$ among adults with diabetes, hypertension or eGFR $<60 \mathrm{~mL} / \mathrm{min} / 1.73 \mathrm{~m}^{2}$ in the general community, urine dipstick results of $1+$ or greater had mean sensitivity of $59 \%-64 \%$, mean specificity of $93 \%-95 \%$, mean positive predictive values of $66 \%-72 \%$ and mean negative predictive values of $90 \%-94 \%$. The corresponding values for UACR $\geqslant 300 \mathrm{mg} / \mathrm{g}$ were $98 \%-100 \%$, $84 \%$ $90 \%, 16 \%-24 \%$ and $100 \% .{ }^{41}$

In relation to specimen collection, while timed urine collection is considered the gold standard for evaluating albuminuria or proteinuria, it has logistical difficulties. In routine clinical practice, 24-hour collections are inconvenient to patients and are subject to significant inaccuracies due to incomplete collection of all urine voided, timing errors and appreciable intra-individual variation due to varying activity, hydration and diet. $^{22}$ Measurement of albuminuria in a first morning void specimen provides acceptable accuracy and reliability in most circumstances. ${ }^{42,43}$ Since urinary protein excretion follows a circadian pattern and tends to be highest in the afternoon, UACR tests are most accurate when performed on early morning (first-void) urine specimens. ${ }^{42}$ However, a number of studies have shown that random urine specimens are acceptable if first-void specimens are impractical. ${ }^{42-44}$ Investigations have also shown that correction of urinary albumin measurements for urinary creatinine excretion accounts for variation in urinary concentration, and results in better correlation with timed urine results. ${ }^{42,45}$

Recommendation: The preferred method for assessment of albuminuria in both diabetic and non-diabetic individuals is urinary albumin-to-creatinine ratio (UACR) measurement in a first-void (first morning) spot specimen. Where a first-void specimen is not possible or practical, a random spot urine specimen for UACR is acceptable. (Evidence level, 1C)

\section{Target population for initial testing for CKD using UACR}

The available evidence does not support screening the entire Australian population for albuminuria, proteinuria or CKD. ${ }^{40}$ Instead, current recommendations strongly advocate targeted opportunistic testing in the primary care setting. ${ }^{46}$ All adults attending an appointment with their health care practitioner should be assessed for CKD risk factors as part of routine primary health encounters. Diabetes mellitus, hypertension, obesity, current smoking, 


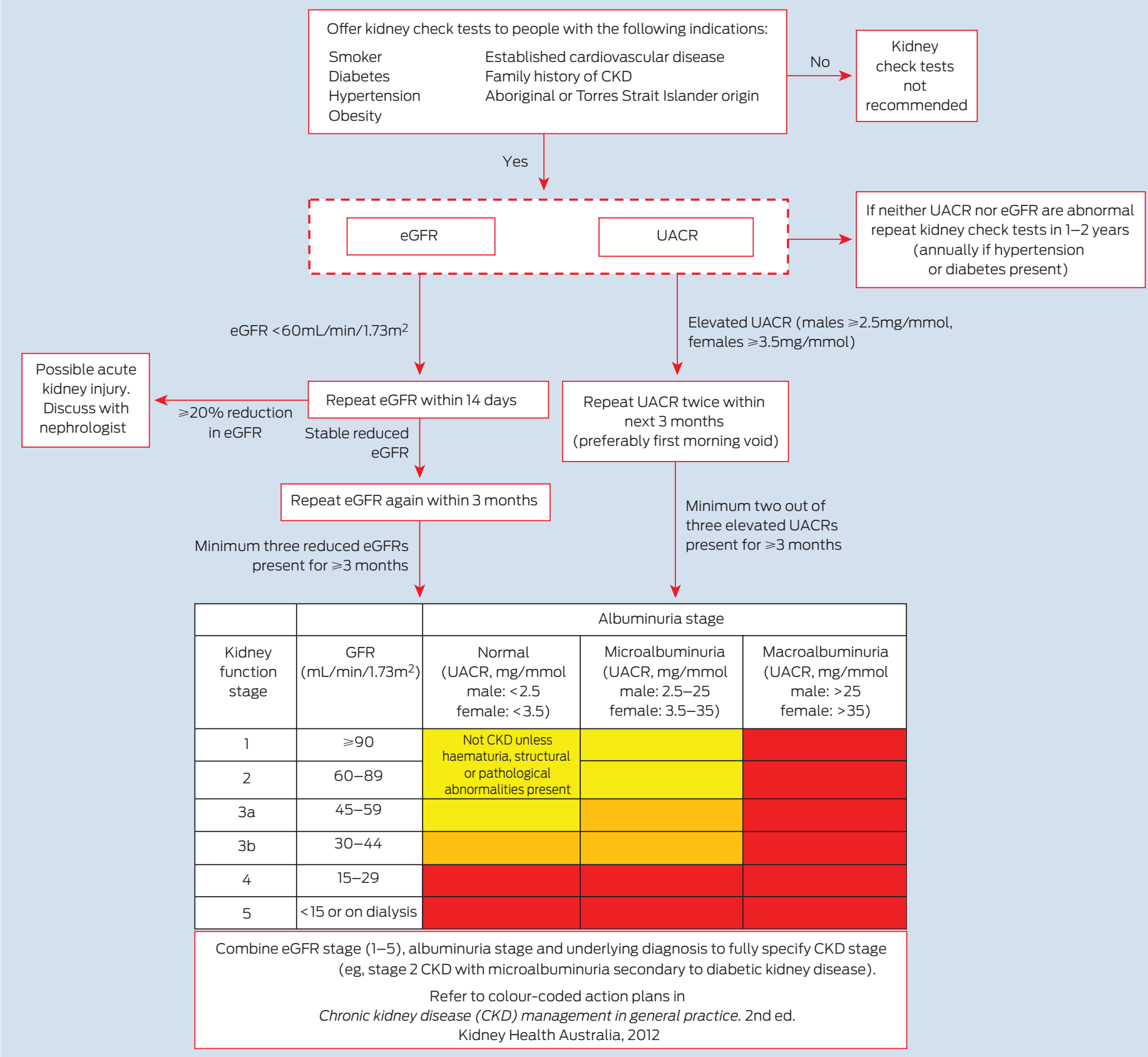

$\mathrm{CKD}=$ chronic kidney disease. eGFR = estimated glomerular filtration rate. $U A C R=$ urinary albumin-to-creatinine ratio.

established cardiovascular disease, family history of CKD and Aboriginal and Torres Strait Islander origin are risk factors for CKD (Box 2). The Kidney Check Australia Taskforce $^{47}$ and the RACGP "red book" ${ }^{48}$ recommend that patients with one or more of these risk factors should undergo assessment of UACR and eGFR every 1 to 2 years (annually for individuals with diabetes or hypertension). While being aged 60 years or over is considered to be a risk factor for CKD, in the absence of other risk factors it is not necessary to routinely test these individuals for kidney disease.

Recommendation: Adults with one or more risk factors for CKD should be assessed using UACR and eGFR every 1-2 years, depending on their risk-factor profile. (Evidence level, 2C)

\section{Standard cut-points for microalbuminuria and macroalbuminuria based on UACR measurement}

A recent survey of Australasian pathology laboratories showed significant variation in the reported cut-points defining microalbuminuria and macroalbuminuria, with many not reporting sex-specific cut-points. ${ }^{16}$ Since urinary creatinine excretion is influenced by muscle mass, urinary creatinine excretion in men is, on average, $40 \%-50 \%$ higher than in women. ${ }^{49-51}$ The mean cut-off for conversion of UACR to albumin excretion rate (AER) at the 


\begin{tabular}{|c|c|c|c|}
\hline & Sex & Microalbuminuria & Macroalbuminuria \\
\hline \multirow[t]{2}{*}{ UACR } & Men & $2.5-25 \mathrm{mg} / \mathrm{mmol}$ & $>25 \mathrm{mg} / \mathrm{mmol}$ \\
\hline & Women & $3.5-35 \mathrm{mg} / \mathrm{mmol}$ & $>35 \mathrm{mg} / \mathrm{mmol}$ \\
\hline $\begin{array}{l}\text { 24-h urinary } \\
\text { albumin }\end{array}$ & Either & 30-300 mg/day & > 300 mg/day \\
\hline
\end{tabular}

threshold to diagnose microalbuminuria $(20 \mu \mathrm{g} / \mathrm{min}$ or $30 \mathrm{mg} /$ day) is greater in women (UACR, $2.8-4.2 \mathrm{mg} / \mathrm{mmol}$ ) than in men (UACR, $1.8-3.0 \mathrm{mg} / \mathrm{mmol}){ }^{45,49-57}$ Similar results have been found when using UACR thresholds to predict proteinuria of 0.5 and $1 \mathrm{~g} /$ day. ${ }^{58}$ As a result, international practice guidelines support adjustment of UACR categories by sex, with lower threshold levels used for men than women. ${ }^{20-22,30,57}$ The definitions and cut-points in Box 3 align with the Australian National Health and Medical Research Council (NHMRC) guidelines for diagnosis, prevention and management of CKD in type 2 diabetes. $^{20}$

Urinary creatinine excretion and muscle mass are also influenced by ethnicity and age. However, there is insufficient evidence to recommend ethnicity-specific or agespecific cut-points for UACR. Indexing albuminuria or proteinuria against eGFR has been suggested, ${ }^{59}$ but there is no evidence to support this practice.

Recommendation: All pathology laboratories should report cut-points for microalbuminuria and macroalbuminuria according to the standard definitions. Sexspecific cut-points for UACR measurements are recommended. (Evidence level, 1C)

\section{Number of UACR measurements required to establish the presence of persistent albuminuria}

Transient albuminuria in the primary care setting can be influenced by a number of pre-existing factors (Box 4). ${ }^{20,29}$ These factors, together with the high intra-individual coefficient of variation of albuminuria $(30 \%-50 \%)$ whether measured as UACR or AER, require that several measurements are undertaken to allow accurate categorisation of albuminuria status. If a UACR is abnormal on at least two occasions over at least 3 months, CKD is present (Box 2). If the first positive UACR is a random spot, then repeat tests should ideally be first morning void specimens. If an initial $\mathrm{UACR}$ test is negative, then repeat testing is not required until the next recommended testing interval.

Recommendation: A positive UACR test should be repeated to confirm persistence of albuminuria. CKD is present if two out of three tests (including the initial test) are positive. If the first positive UACR is a random spot (as it may be for opportunistic testing), then repeat tests should ideally be first morning void specimens. (Evidence level, 1C)

\section{Estimating urinary protein excretion from urinary albumin excretion or vice versa}

The relationship of albuminuria to proteinuria is complex. The simple concept that, for clinical purposes, albuminuria and proteinuria could be considered equivalent is no longer sustainable. Macroalbuminuria is typically associated with proteinuria, but microalbuminuria may not be detected as elevated urinary protein, depending on the decision points selected. ${ }^{29}$ In the AusDiab study, ${ }^{60}$ the proportion of urinary protein accounted for by albumin was shown to progressively increase as total proteinuria increased. A recent study of 6761 urine specimens reported considerable scatter of UACR values compared with PCR values, ${ }^{61}$ while another study of 579 fresh urine specimens with microscopic haematuria ( $\geqslant 5$ red blood cells/highpower field) observed that the urinary albumin-to-protein ratio was significantly higher in patients with glomerular abnormality than in those with non-glomerular abnormality $(0.73 \pm 0.11 \mathrm{mg} / \mathrm{mg}$ versus $0.41 \pm 0.14 \mathrm{mg} / \mathrm{mg} ; \quad P$ <0.001). ${ }^{62}$ A retrospective, observational cohort study of 1696 patients with CKD at a single renal unit showed that the relationship between UACR and UPCR is non-linear and that 24-hour urinary protein could not be adequately predicted from UACR. ${ }^{58}$ Thus, generating an "estimated UPCR" or "estimated" 24-hour urinary total protein from a UACR is likely to result in significant error.

Recommendation: There is no reliable way of estimating urinary protein excretion from urinary albumin concentration or vice versa. (Evidence level, 1C)

\section{Estimating urinary albumin excretion rate from UACR}

The relationship between UACR and AER is influenced by determinants of muscle mass, including sex, race, age, body surface area and serum creatinine concentration. ${ }^{49}$ Studies among patients with diabetes have shown that the use of UACR versus AER provided reasonable agreement for the classification of macroalbuminuria, but yielded important differences in the classification of microalbuminuria. ${ }^{49}$ The level of agreement with AER for microalbuminuria was not appreciably improved by the use of an AER-estimating equation that incorporated sex or other covariates (age, body surface area, serum creatinine level, systolic blood pressure, use of an angiotensin-converting enzyme inhibitor or angiotensin receptor blocker) ${ }^{49} \mathrm{Nev}-$ ertheless, the effects of the interventions assessed in the Diabetes Control and Complications Trial and the association with glycaemia were not affected by which measurement method (ACR, estimated AER or AER) was employed. ${ }^{49}$ The working group considered that, until albumin measurements are standardised and the impact of AER-estimating equations on albuminuria classification are assessed in diverse, widely representative populations,

4 Factors other than chronic kidney disease known to affect
urinary albumin excretion
- Urinary tract infection
- High dietary protein intake
- Congestive cardiac failure
- Acute febrile illness
- Heavy exercise within 24 hours
- Menstruation or vaginal discharge
Drugs (especially non-steroidal anti-inflammatory drugs,
receptonsin-converting enzyme inhibitors, angiotensin


the use of estimated AER cannot be recommended, and ACR should be used as a defined tool in its own right.

Recommendation: Use of estimated albumin excretion rate derived from the UACR is not recommended. (Evidence level, 1C)

\section{Role of pathology laboratories}

Laboratories should recommend a first morning void specimen for ACR as the preferred test for identification of kidney damage in all settings, although random specimens should be accepted if first morning void specimens are impractical. Collection advice should note the need to avoid the factors listed in Box 4, especially on follow-up testing of positive specimens. UACR should be reported in $\mathrm{mg} / \mathrm{mmol}$ to one decimal place and the sex-specific ratio ranges (Box 3) should be used as reference intervals. Laboratories should ensure the assays for urinary albumin and creatinine are suited for purpose such that assay imprecision, bias and analytic specificity will not adversely affect clinical decision making. Laboratories should develop standardised reporting so that doctors receive the same medical information irrespective of the laboratory used.

Recommendation: All pathology laboratories in Australia should implement the relevant recommendations contained in this document as a vital component of an integrated national approach to CKD detection.

\section{Conclusion}

Identification of CKD relies on correct requesting, performance, reporting and interpretation of laboratory tests. There is now overwhelming evidence that optimal detection and risk stratification in CKD requires consideration of both urinary albumin and eGFR (see recommendations of the Australasian Creatinine Consensus Working Group ${ }^{63}$ ). Standardisation of the UACR as the preferred test for albuminuria in the initial assessment of all individuals with possible CKD is an important step towards bringing the best available clinical evidence to routine patient care. The testing process involves many aspects of care, including vital input from clinicians, pathologists, laboratory scientists and researchers, and the involvement of all groups is required to maximise the opportunities for improving kidney and cardiovascular health in Australia.

Competing interests: David Johnson has received consulting fees or honoraria from Amgen, Roche, Shire, Genzyme, Boehringer-Ingelheim, Baxter Healthcare and Fresenius Medical Care; support for travel to meetings from Baxter, Amgen, Roche and Shire; and payment for development of educational presentations from the Australian College of Rural and Remote Medicine and the Northern Territory Division of General Practice.

Graham Jones has received research support from Roche Diagnostics and support for travel to meetings from Roche Diagnostics and Bio-Rad.

Stephen Chadban has received research support, travel assistance, consulting fees or honoraria from Amgen, Roche, Novartis, Genzyme, Wyeth and Bristol Myers Squibb.

Richard Maclsaac has received speaker's fees or travel support to attend meetings from Boehringer-Ingelheim, AstraZeneca, Eli Lilly, MSD, Novartis, Novo Nordisk and Sanofi Aventis. He has received grants from Novo Nordisk.

Provenance: Not commissioned; externally peer reviewed.

1 Johnson D; Caring for Australians with Renal Impairment. The CARI guidelines: evaluation of renal function. Nephrology (Carlton) 2005; 10 Suppl 4: S133-S176.

2 Chadban SJ, Briganti EM, Kerr PG, et al. Prevalence of kidney damage in Australian adults: the AusDiab kidney study. J Am Soc Nephrol 2003; 14 (7 Suppl 2): S131-S138.
3 White SL, Polkinghorne KR, Atkins RC, Chadban SJ. Comparison of the prevalence and mortality risk of CKD in Australia using the CKD Epidemiology Collaboration (CKD-EPI) and Modification of Diet in Renal Disease (MDRD) Study GFR estimating equations: the AusDiab (Australian Diabetes, Obesity and Lifestyle) Study. Am J Kidney Dis 2010; 55: 660-670.

4 Johnson DW. Evidence-based guide to slowing the progression of early renal insufficiency. Intern Med J 2004; 34: 50-57.

5 Mathew TH; Australasian Creatinine Consensus Working Group. Chronic kidney disease and automatic reporting of estimated glomerular filtration rate: a position statement. Med J Aust 2005; 183: 138-141.

6 Mathew TH, Johnson DW, Jones GR; Australasian Creatinine Consensus Working Group. Chronic kidney disease and automatic reporting of estimated glomerular filtration rate: revised recommendations. Med J Aust 2007; 187: 459-463.

7 Chronic Kidney Disease Prognosis Consortium. Association of estimated glomerular filtration rate and albuminuria with all-cause and cardiovascular mortality in general population cohorts: a collaborative meta-analysis. Lancet 2010; 375: 2073-2081.

8 Ninomiya T, Perkovic V, de Galan BE, et al; ADVANCE Collaborative Group. Albuminuria and kidney function independently predict cardiovascular and renal outcomes in diabetes. J Am Soc Nephrol 2009; 20: 1813-1821.

9 Iseki K, Ikemiya Y, Iseki C, Takishita S. Proteinuria and the risk of developing end-stage renal disease. Kidney Int 2003; 63: 1468-1474.

10 Hallan SI, Ritz E, Lydersen S, et al. Combining GFR and albuminuria to classify CKD improves prediction of ESRD. J Am Soc Nephrol 2009; 20: 1069-1077.

11 Hoy WE, Wang Z, VanBuynder P, et al. The natural history of renal disease in Australian Aborigines. Part 2. Albuminuria predicts natural death and renal failure. Kidney Int 2001; 60: 249-256.

12 Hillege HL, Fidler V, Diercks GF, et al; Prevention of Renal and Vascular End Stage Disease (PREVEND) Study Group. Urinary albumin excretion predicts cardiovascular and noncardiovascular mortality in general population. Circulation 2002; 106: 1777-1782.

13 Iseki K, Kinjo K, Iseki C, Takishita S. Relationship between predicted creatinine clearance and proteinuria and the risk of developing ESRD in Okinawa, Japan. Am J Kidney Dis 2004; 44: 806-814.

14 Kissmeyer L, Kong C, Cohen J, et al. Community nephrology: audit of screening for renal insufficiency in a high risk population. Nephrol Dial Transplant 1999; 14:2150-2155.

15 Jones G. Urine albumin sampling and reporting - current practice in Australasia. The Clinical Biochemist Newsletter 2006; 163: 31-32. http:// oldsite.aacb.asn.au/getfile/3123 (accessed Jul 2012).

16 Jones GR. Laboratory reporting of urine protein and albumin. Clin Biochem Rev 2011; 32: 103-107.

17 Atkins D, Best D, Briss PA, et al; GRADE Working Group. Grading quality of evidence and strength of recommendations. BMJ 2004; 328: 1490.

18 Uhlig K, Macleod A, Craig J, et al. Grading evidence and recommendations for clinical practice guidelines in nephrology. A position statement from Kidney Disease: Improving Global Outcomes (KDIGO). Kidney Int 2006; 70 : 2058-2065.

19 American Diabetes Association. Standards of medical care in diabetes--2006. Diabetes Care 2006; 29 Suppl 1: S4-S42.

20 Chadban S, Howell M, Twigg S, et al. National evidence based guideline for diagnosis, prevention and management of chronic kidney disease in type 2 diabetes. Canberra: Diabetes Australia and NHMRC, 2009. http:// www.nhmrc.gov.au/files_nhmrc/publications/attachments/dil8-diabeteskidney-disease.pdf (accessed Apr 2012).

21 Crowe E, Halpin D, Stevens P; Guideline Development Group. Early identification and management of chronic kidney disease: summary of NICE guidance. BMJ 2008; 337: al530.

22 National Collaborating Centre for Chronic Conditions. Chronic kidney disease: national clinical guideline for early identification and management in adults in primary and secondary care. London: Royal College of Physicians, 2008. http:/ /www.ncbi.nlm.nih.gov/books/NBK51773 (accessed Apr 2012).

23 Methven S, MacGregor MS, Traynor JP, et al. Comparison of urinary albumin and urinary total protein as predictors of patient outcomes in CKD. Am J Kidney Dis 2010; 57: 21-28.

24 de Zeeuw D. Albuminuria, not only a cardiovascular/renal risk marker, but also a target for treatment? Kidney Int Suppl 2004; (92): S2-S6.

25 Hallan S, Astor B, Romundstad S, et al. Association of kidney function and albuminuria with cardiovascular mortality in older vs younger individuals: the Hunt II Study. Arch Intern Med 2007; 167: 2490-2496.

26 Asselbergs FW, Diercks GF, Hillege HL, et al. Effects of fosinopril and pravastatin on cardiovascular events in subjects with microalbuminuria. Circulation 2004; 110: 2809-2816.

27 Färbom P, Wahlstrand B, Almgren P, et al. Interaction between renal function and microalbuminuria for cardiovascular risk in hypertension: the Nordic Diltiazem Study. Hypertension 2008; 52: 115-122.

28 Lamb EJ, MacKenzie F, Stevens PE. How should proteinuria be detected and measured? Ann Clin Biochem 2009; 46: 205-217.

29 Miller WG, Bruns DE, Hortin GL, et al; National Kidney Disease Education Program-IFCC Working Group on Standardization of Albumin in Urine. Current 
issues in measurement and reporting of urinary albumin excretion. Clin Chem 2009; 55: 24-38.

30 Scottish Intercollegiate Guidelines Network. Diagnosis and management of chronic kidney disease: a national clinical guideline. Edinburgh: Scottish Intercollegiate Guidelines Network, 2008. http://www.sign.ac.uk/pdf/ sign103.pdf (accessed Apr 2012)

31 Eckardt KU, Berns JS, Rocco MV, Kasiske BL. Definition and classification of CKD: the debate should be about patient prognosis - a position statement from KDOQI and KDIGO. Am J Kidney Dis 2009; 53: 915-920.

32 Levey AS, Eckardt KU, Tsukamoto Y, et al. Definition and classification of chronic kidney disease: a position statement from Kidney Disease: Improving Global Outcomes (KDIGO). Kidney Int 2005; 67: 2089-2100.

33 National Kidney Foundation. K/DOQI clinical practice guidelines for chronic kidney disease: evaluation, classification, and stratification. Am J Kidney Dis 2002; 39 (2 Suppl 1): Sl-S266.

34 Saudan PJ, Brown MA, Farrell T, Shaw L. Improved methods of assessing proteinuria in hypertensive pregnancy. Br J Obstet Gynaecol 1997; 104: 11591164.

35 Kidney Health Australia. Chronic kidney disease (CKD) management in general practice. Melbourne: Kidney Health Australia, 2007.

36 National Aboriginal Community Controlled Health Organisation. National guide to a preventive health assessment in Aboriginal and Torres Strait Islander peoples. South Melbourne: Royal Australian College of General Practitioners, 2005. http://www.naccho.org.au/Files/Documents/ National\%20guide\%20to\%20preventive\%20health\%20assessment.pdf (accessed Apr 2012).

37 National Heart Foundation. Hypertension management guide for doctors, 2004. Deakin, ACT: National Heart Foundation of Australia, 2003.

38 Royal Australian College of General Practitioners. Guidelines for preventive activities in general practice. 7th ed. South Melbourne: RACGP, 2009. http:// www.racgp.org.au/Content/NavigationMenu/ClinicalResources/ RACGPGuidelines/TheRedBook/redbook_7th_edition_May_2009.pdf (accessed Apr 2012).

39 Caring for Australians with Renal Impairment. The CARI guidelines. Urine protein as diagnostic test: performance characteristics of tests used in the initial evaluation of patients at risk of renal disease. Nephrology (Carlton) 2004: 9 Suppl 3: S8-S14.

40 Craig JC, Barratt A, Cumming R, et al. Feasibility study of the early detection and treatment of renal disease by mass screening. Intern Med J 2002; 32: 6-14.

41 White S, Yu R, Craig JC, et al. Diagnostic accuracy of urine dipsticks for detection of albuminuria in the general community. Am J Kidney Dis 2011; 58 : $19-28$.

42 Witte EC, Lambers Heerspink HJ, de Zeeuw D, et al. First morning voids are more reliable than spot urine samples to assess microalbuminuria. J Am Soc Nephrol 2009; 20: 436-443.

43 Price CP, Newall RG, Boyd JC. Use of protein:creatinine ratio measurements on random urine samples for prediction of significant proteinuria: a systematic review. Clin Chem 2005; 51: 1577-1586.

44 Côté AM, Brown MA, Lam E, et al. Diagnostic accuracy of urinary spot protein:creatinine ratio for proteinuria in hypertensive pregnant women: systematic review. BMJ 2008; 336: 1003-1006.

45 Bakker AJ. Detection of microalbuminuria. Receiver operating characteristic curve analysis favors albumin-to-creatinine ratio over albumin concentration. Diabetes Care 1999; 22: 307-313.
46 Johnson DW, Mathew T. Managing chronic kidney disease. Medicine Today 2007; 8: 37-45. http://www.medicinetoday.com.au/home/article/view/648 (accessed Jul 2012)

47 Kidney Health Australia. Chronic kidney disease (CKD) management in general practice. 2nd ed. Melbourne: KHA, 2012.

48 Royal Australian College of General Practitioners. Guidelines for preventive activities in general practice. 8th ed. South Melbourne: RACGP, 2012. In press.

49 Younes N, Cleary PA, Steffes MW, et al; DCCT/EDIC Research Group. Comparison of urinary albumin-creatinine ratio and albumin excretion rate in the Diabetes Control and Complications Trial/Epidemiology of Diabetes Interventions and Complications study. Clin J Am Soc Nephrol 2010; 5: 12351242. doi: 10.2215/CJN.07901109.

50 Houlihan CA, Tsalamandris C, Akdeniz A, Jerums G. Albumin to creatinine ratio: a screening test with limitations. Am J Kidney Dis 2002; 39: 1183-1189.

51 Kramer HM, Hsu CY, Curhan G. Need for sex-specific ACR. Am J Kidney Dis 2002; 40: 435-436.

52 Warram JH, Gearin G, Laffel L, Krolewski AS. Effect of duration of type I diabetes on the prevalence of stages of diabetic nephropathy defined by urinary albumin/creatinine ratio. J Am Soc Nephrol 1996; 7: 930-937.

53 Mattix HJ, Hsu CY, Shaykevich S, Curhan G. Use of the albumin/creatinine ratio to detect microalbuminuria: implications of sex and race. J Am Soc Nephrol 2002; 13: 1034-1039.

54 de Boer IH, Astor BC, Kramer H, et al. Mild elevations of urine albumin excretion are associated with atherogenic lipoprotein abnormalities in the Multi-Ethnic Study of Atherosclerosis (MESA). Atherosclerosis 2008; 197: 407-414.

55 de Boer IH, loannou GN, Kestenbaum B, et al. 25-Hydroxyvitamin D levels and albuminuria in the Third National Health and Nutrition Examination Survey (NHANES III). Am J Kidney Dis 2007; 50: 69-77.

56 Incerti J, Zelmanovitz T, Camargo JL, et al. Evaluation of tests for microalbuminuria screening in patients with diabetes. Nephrol Dial Transplant 2005; 20: 2402-2407.

57 Mogensen CE, Keane WF, Bennett PH, et al. Prevention of diabetic renal disease with special reference to microalbuminuria. Lancet 1995; 346: 1080 1084.

58 Methven S, MacGregor MS, Traynor JP, et al. Assessing proteinuria in chronic kidney disease: protein-creatinine ratio versus albumin-creatinine ratio. Nephrol Dial Transplant 2010; 25: 2991-2996.

59 Ellam TJ, El Nahas M. Proteinuria thresholds are irrational: a call for proteinuria indexing. Nephron Clin Pract 2011; 118: c217-c224.

60 Atkins RC, Briganti EM, Zimmet PZ, Chadban SJ. Association between albuminuria and proteinuria in the general population: the AusDiab Study. Nephrol Dial Transplant 2003; 18: 2170-2174.

61 Mclntyre NJ, Taal MW. How to measure proteinuria? Curr Opin Nephrol Hypertens 2008; 17: 600-603.

62 Ohisa N, Yoshida K, Matsuki R, et al. A comparison of urinary albumin-total protein ratio to phase-contrast microscopic examination of urine sediment for differentiating glomerular and nonglomerular bleeding. Am J Kidney Dis 2008; 52: 235-241.

63 Australasian Creatinine Consensus Working Group. Chronic kidney disease and automatic reporting of estimated glomerular filtration rate: new developments and revised recommendations. Med J Aust 2012; 197: 224-225. 